\title{
BACIAS HIDROGRÁFICAS, PAGAMENTO POR SERVIÇOS AMBIENTAIS E NECESSIDADE DE MONITORAMENTO: O CASO DO MUNICÍPIO EM ITABIRITO - MG
}

\author{
Edson Ricardo Saleme* \\ Silvia Elena Barreto Saborita**
}

\begin{abstract}
Resumo: O trabalho tem como objetivo verificar como os consórcios de águas processam mecanismos de serviços ambientais e quais são as formas de monitoramento disponíveis nos comitês de bacias para verificar a situação do objeto da outorga, nas hipóteses de serviços ambientais, considerando as mudanças climáticas. Aqui se dará enfoque ao funcionamento do Comitê PCJ dos Rios Piracicaba, Capivari e Jundiaí como modelo adequado de gestão e o que está atualmente ocorre na região metropolitana de Belo Horizonte pela falta de monitoramento, que gera redução significativa na vazão das nascentes em toda a região. Será empregado o método hipotético-dedutivo e a metodologia bibliográfica.
\end{abstract}

Palavras-chave: Sustentabilidade; Recursos hídricos, Bacias hidrográficas; Mudanças climáticas; Gestão adequada.

\section{HYDROGRAPHIC BASINS, PAYMENT FOR ENVIRONMENTAL SERVICES AND THE NEED OF MONITORING: THE CASE OF ITABIRITO - MG}

\begin{abstract}
The objective of this paper is to verify how water consortium process environmental services and which forms of monitoring are available in basin committees to verify the status of the granting object when environmental services are granted, also considering climate change. The functioning of the PCJ Piracicaba, Capivari and Jundiaí Rivers Committee is analysed as an appropriate management model and what is currently occurring in the metropolitan area of Belo Horizonte due to the lack of monitoring, which has generated a significant reduction in the flow of water. The hypothetical-deductive method and the bibliographic methodology will be used.
\end{abstract}

Keywords: Sustainability; Water resources; River basins; Climate changes; Proper management.

\footnotetext{
* Professor Doutor em Direito de Estado pela USP, professor do Curso stricto sensu em Direito Ambiental Internacional na Unisantos. Consultor do IBAMA. Advogado em São Paulo. Email: ricasal@uol.com.br

** Doutoranda em Direito Ambiental Internacional pela Unisantos. Mestre em Direito Ambiental. Professor do Curso de Direito da Universidade Paulista. Advogada em São Paulo. Email: silvia.saborita@gmail.com
} 


\section{INTRODUÇÃO}

O desenvolvimento sustentável, conceito obtido após diversos estudos oriundos de reuniões promovidas pela Organização das Nações Unidas em defesa do ambiente, é uma proposta de desenvolvimento para a humanidade perante a crise social e ambiental pela qual o mundo tem atravessado e cujo agravamento se observou a partir da segunda metade do século XX. Na diversa apreciação dos recursos ambientais, os recursos hídricos passaram a ser considerados bens econômicos por meio da outorga de serviços por órgãos especializados, indicados em normas, responsáveis igualmente pelo seu gerenciamento e manutenção.

Nesse sentido a exploração da água pelo homem levou à promoção do gerenciamento de recursos hídricos, em face da poluição visível nos corpos d'água, seja ela que situação estiver. Nos termos do que dispõe a CDB de 1992 e o art. 225 da Constituição Federal, as futuras gerações devem receber um meio ambiente condigno em que possam se desenvolver adequadamente. Nesse sentido, quanto maior o número de conscientização de pessoas da necessidade de preservação é realmente viável imaginar que aquelas gerações herdarão realmente um ambiente próprio, viável para suas vidas.

Esse quadro estabelece a problemática em que a população deveria estar envolvida, acompanhando, juntamente com os órgãos responsáveis pelo gerenciamento de recursos naturais, as decisões relacionadas ao uso de água e de sua gestão. Assim, essa população deveria ser devidamente consultada, diante de um quadro informativo em que se posiciona o grau de impacto que determinadas gestões podem gerar, e assim tomar decisões conscientes do que pode ou não ocorrer com o uso da água.

A gestão eficiente dos recursos hídricos é primordial para que o bem ambiental objeto deste estudo, contemplado na Constituição Federal, possa ter seu uso adaptado aos diversos interesses e usos envolvidos. Assim, a água deve ser mantida em níveis adequados para que os ecossistemas que dela dependam possam ser supridos em suas necessidades. Nesse contexto, o planejamento estabelece os limites do uso da água e a possibilidade ou não de sua concessão. Talvez isso possa solucionar ou verificar a diminuição significante da água em bacias hidrográficas e não venham a sofrer o ocorrido na bacia situada na Região Metropolitana de Belo Horizonte, cuja diminuição no nível de águas veio a ser objeto de diversas demandas e estudos para fins de monitoramento da outorga. 
A legislação brasileira é específica na proteção de águas e estabelece padrões de lançamento de efluentes a fim de não descurar do escoamento de água em determinados ecossistemas. A manutenção saudável deles é imprescindível para o que se quer alcançar com o desenvolvimento sustentável. A gestão das águas outorgou aos órgãos do Poder Executivo a missão de controle. Assim, o Conselho Nacional de Gestão dos Recursos Hídricos (CNHR) é o responsável por elaborar e coordenar a Política Nacional de Recursos Hídricos (PNRH).

A ANA (Agência Nacional de Águas) está encarregada da coordenação do Sistema Nacional de Gerenciamento dos Recursos Hídricos (SINGREH). Entre os órgãos que compõe esse sistema estão o Conselho Nacional de Recursos Hídricos, Conselhos de Recursos Hídricos dos Estados e DF, Comitês de Bacias Hidrográficas e Agências de Bacias Hidrográficas.

Este trabalho tem como objetivo verificar como os consórcios PCJ processam mecanismos de serviços ambientais e se há monitoramento efetivo nos comitês de bacias, em especial naquela situada na Região Metropolitana de Belo Horizonte. É possível afirmar que os interesses coletivos predominam perante o privado, no qual o mercado estaria em primeiro plano? Os comitês de bacias estão tendo problemas com o esgotamento de recursos naturais diante de pedidos de empresas? Como funciona o PSA e como o clima pode interferir na qualidade das águas?

É sabido que o Comitê de Bacia Hidrográfica é o fórum em que se discutem os problemas locais relacionados à bacia especifica. Os comitês devem funcionar com equipe técnica capaz de verificar a realidade do impacto que surgirá a partir de determinada intervenção antrópica, em termos de volume de água e se a ação pode ou não impactar o ecossistema envolvido. A priori é fundamental a participação da sociedade civil que se encarregará da opinião dos setores existentes na região diante da ação que se quer efetivar. Além disso, estudos técnicos devem garantir que os recursos ambientais não se esgotarão em relação ao uso conferido a título de serviço ambiental que o comitê venha a eventualmente contratar.

O trabalho primeiramente fará uma breve análise relacionada à Bacia PCJ dos Rios Piracicaba, Capivari e Jundiaí, que abrange a circunscrição de 76 municípios sendo que 62 deles têm sede nas áreas de drenagem da região. Do total de municípios 58 estão no Estado de São Paulo e 4 em Minas Gerais. Entre as municipalidades que possuem território na região PCJ e sede em outras bacias 13 estão em São Paulo e somente um deles em Minas Gerais. Neste trabalho se buscará relatar como processa o gerenciamento de recursos hídricos e sua atuação em face do 
desenvolvimento sustentável e diante de projetos privados que querem naquela região se assentar. Aqui se fará uma análise em casos concretos, tal como o caso da distribuidora dos refrigerantes “coca-cola” tanto na Bacia PCJ como na situada na Região Metropolitana de Belo Horizonte. Enfoque especial será ao fato relacionado ao esgotamento de recursos e a problemas recentemente foram reportados diante da realidade da prestação dos serviços ambientais e impasses gerados pelo mau dimensionamento por parte dos responsáveis pela concessão.

Também será aqui verificada como a questão climática interfere efetivamente na qualidade da água em diversos sentidos: físico, químico, biológico, entre outros.

Neste trabalho se empregará metodologia bibliográfica e documental para expor e discutir aspectos relevantes da Bacia em discussão e como os trabalhos têm se desenvolvido no decorrer de sua existência.

\section{1 - RECURSOS HÍDRICOS E LEGISLAÇÃO NACIONAL}

O Código de Águas de 1934 classificou as categorias jurídicas, discriminou os usos e respectivos preceitos, além de assegurar os interesses relevantes da sociedade. A Constituição Federal vigente estabeleceu que todas as águas são de domínio público, dos estados federados (art. 26,I) e da União (art.20, III a VIII). Não há qualquer previsão acerca de águas particulares ou mesmo comuns existentes em legislações anteriores. Nos termos da Lei n ${ }^{\circ}$ 9.433, de 1997 a água sequer faz parte do patrimônio privado do Poder Público. Está expresso em seu artigo 18 que "a outorga não implica a alienação parcial das águas que são inalienáveis, mas o simples direito de uso".

O Comitê de Bacia Hidrográfica é o órgão colegiado que possui atribuições normativas, deliberativas e consultivas que devem ser exercidas no âmbito da bacia hidrográfica. Deve ser constituído pelos representantes dos governos municipais, estaduais e federal, pelos representantes dos usuários e da sociedade civil organizada, nos termos do art. 39 da Lei 9.433, de 1997.

Nas palavras de Mascarenhas (2006) esse comitê ou colegiado funciona como um "parlamento das águas" e atua como instância direta dos grupos decisórios organizados em cada bacia. É instituído com a missão de abrigar os processos participativos de gestão das águas em esfera em que os interessados possam negociar. São Paulo destacou-se por ser um dos primeiros estados a adotar a referida Lei e implementar os respectivos comitês. As cidades banhadas pelas

Rev. de Direito Agrário e Agroambiental | e-ISSN: 2526-0081 | Porto Alegre | v. 4 | n. 2 | p. 55 - 70 | Jul/Dez. 2018 
Bacias dos rios Piracicaba e Capivari criaram, em 1989, um consórcio, segundo Cristina Bernardes Ribeiro (2006, p.20). Essa foi uma iniciativa pioneira no país com o propósito de promover a recuperação ambiental dos rios, integração regional e o planejamento do desenvolvimento da Bacia. Este Comitê experimentou fases diversas e sua evolução gradual. As dificuldades que esses comitês enfrentam são múltiplas que vão desde questões de natureza política até de ordem socioeconômica. O comitê PCJ (Piracicaba, Capivari e Jundiaí) iniciouse em 18 de novembro de 1993, com a promulgação da Lei nº 7.663.

Nas palavras de Coimbra et al (1999) o comitê de bacia hidrográfica deve ser o fórum em que ocorrem discussões locais e problemas específicos inerentes à Bacia. Com o ordenamento de prioridade de intenções o dimensionamento dos recursos financeiros e a integração com os programas setoriais e locais. Diante desses elementos esse comitê funciona de forma disciplinar e tecnicamente próprio para gerir as águas.

O comitê de bacia hidrográfica é um lócus em que se discutem o uso das águas em que há opinião de setores interessados na exploração da água, mas também preocupados com elementos socioambientais relevantes para determinada região. A outorga merece um acompanhamento das atividades para que os elementos sejam preservados e se mantenham dentro da sustentabilidade esperada.

\section{O COMITÊ PCJ (PIRACICABA, CAPIVARI E JUNDIAÍ)}

Este comitê pode ser considerado referência diante de seu amadurecimento como órgão coletivo e responsável pela aplicação dos recursos financeiros provenientes da cobrança pelo uso dos recursos hídricos obtidos nos diversos serviços ambientais cobrados. Também seleciona, entre as propostas apresentadas, as mais vantajosas para ações de execução, como obras e serviços propostos no PIP, especificamente voltadas à restauração ecológica e ao monitoramento da execução. Ele é composto por grande número de municípios e se situa atualmente na Região Metropolitana de Campinas, que concentra destacadas redes de infraestrutura de transportes e também possui complexo viário estadual considerável, isso sem mencionar a linha ferroviária tronco da ferroban e do aeroporto de Viracopos, em Campinas, que atualmente transporta o maior volume de carga do país.

Este Comitê foi criado pela Deliberação Conjunta dos Comitês PCJ n. 008/04 e constituído pela Câmara Técnica de Planejamento. O art. $7^{\circ}$ da Deliberação Conjuntas dos Comitês PCJ 004/03, de 22 de maio de 2003, estabelece as competências a cada um dos entes envolvidos. Nos seus 
termos é possível ao Comitê propor medidas e articular com o Poder Legislativo e Executivo dos estados e municípios envolvidos a fim de se obter as adesões necessárias para as diversas gestões, inclusive para melhor integração organizacional, medidas de ordem geral, as participações na Agência PCJ, entre outras possibilidades.

A Agência de Bacias PCJ foi a primeira ser criada e instalada nos termos das Leis do Estado de São Paulo no 7.663/91 e n 10.020/98. Ao se referir às agências de Bacia e agências de água é fundamental que se mencione o Consórcio Intermunicipal das Bacias dos Rios Piracicaba, Capivari e Jundiaí criado em 1989 e 1998, que passou a exercer a função de agência de bacias, o que perdurou até 2011, quando essa função foi transferida para a Fundação Agência de Bacias PCJ. Em 2011, a Fundação passou a ser entidade delegatária da Agência de Águas. A conformação da estrutura desse comitê segue a composição comum aos comitês de bacia instalados no País. A ANA - Agência Nacional de Águas (2018) esclarece que não há estrutura estabelecida e os comitês podem se amoldar nos termos das peculiaridades locais em que se inserem, não obstante ofereça em seu sítio eletrônico modelo de comitê.

Para melhor explicitar o tema Granziera (2014, p. 281) faz referência ao Comitê e infere que para entender questões relacionadas à integração e à articulação de planos, normas e decisões, importa observar a bacia hidrográfica como unidade territorial de implementação de políticas de recursos hídricos. Mais adiante esclarece que a geografia estabelece o limite territorial da bacia hidrográfica. Além desses detalhes, segue a autora, a divisão administrativa vigente no País refere-se às unidades federativas estabelecidas constitucionalmente, União, Estados, DF e municípios. Mesmo diante dessa realidade, ao instituir os comitês de bacia hidrográfica com funções deliberativas nesses espaços geográficos, a lei introduziu uma nova instância de decisões fora das esferas tradicionais, pois a divisão em bacias hidrográficas pode não observar o território de um município.

"A bacia hidrográfica é a unidade territorial em que a gestão normal das águas deve ocorrer. As águas de uma bacia devem beneficiar prioritariamente os que moram, vivem e trabalham nessa unidade territorial.” Essa afirmativa é de Paulo Affonso Leme Machado (2011, p. 477) que ainda segue em sua ilação afirmando que as portas ainda não se fecham para os que se encontram fora da Bacia. Isso porque também não se vedou que bacias hidrográficas contiguas se unissem em um mesmo comitê de bacias hidrográficas. 
As Agências de Água são entidades criadas para dar o suporte técnico e administrativo aos Comitês de Bacia, exercendo, entre outras, a função de secretaria executiva, nos termos informados pela ANA (2018). Sua viabilidade é assegurada pela cobrança que deve ser feita pelo uso de recursos hídricos da região.

Parte integrante do Sistema Nacional de Gerenciamento dos Recursos Hídricos (SINGREH), a criação dessas agências deve ser solicitada pelo Comitê de Bacia Hidrográfica e autorizada pelo Conselho Nacional ou pelo pelos conselhos estaduais de recursos hídricos. Dentre as atribuições legais das agências, se destacam também: a atualização do cadastro de usuários de água, a elaboração das propostas para os Planos de Recursos Hídricos e a criação de estudos técnicos que possam subsidiar decisões do Comitê.

\section{PAGAMENTO POR SERVIÇOS AMBIENTAIS E O PROBLEMA OCORRIDO EM ITABIRITO - MG}

Os órgãos colegiados que compõe essa arena deliberativa e tratam de temática ambiental foram objeto de destaque na obra de Ana Maria Nusdeo (2018, p. 144), “direito ambiental e economia", onde indicou as dificuldades de formação, bem como dificuldades do Estado em promover oportunidades equânimes aos atores envolvidos, capazes de evitar a reprodução de hierarquias e assimetrias de poder constatadas em outros setores da sociedade. Remarcou a necessidade de processos participativos e da necessidade de aperfeiçoamento do sistema atualmente existente para terem o alcance almejado.

Atualmente um dos instrumentos fundamentais de gestão dos comitês de bacias é a cobrança pelo uso das águas. Está previsto na Política de Recursos Hídricos de São Paulo, instituída pela Lei Estadual 12.183, de 1999. Trata-se de preço público estabelecido em forma de compensação a ser paga pelos usuários de recursos hídricos objetivando a garantia dos padrões de quantidade, qualidade e regime estabelecidos pelos corpos d'água das bacias.

Importante o afirmado por Paulo Haddad (2013) no sentido de que a elaboração e a implementação de sistema de pagamento por serviços ambientais passam por diversas etapas. O mais complexo talvez seja a avaliação econômica desses serviços. Esses serviços podem variar em termos de tangibilidade, utilidade, natureza, entre outras classificações. O importante é que são bens fundamentais para a própria existência das futuras gerações.

Rev. de Direito Agrário e Agroambiental | e-ISSN: 2526-0081 | Porto Alegre | v. 4 | n. 2 | p. 55 - 70 | Jul/Dez. 2018 
A questão da valoração dos serviços ambientais é um dos temais mais complexos, conforme afirmaram Favaro e Rossin (2010). Isso porque isso pressupõe o pagamento para manutenção dos serviços prestados pelo ambiente. O mais complexo, segundo os autores, vem a ser o entendimento de que a perda da biodiversidade ou dos ecossistemas é diferente do cálculo do valor da natureza em sua plenitude, uma vez que esse valor é infinito.

Sob o escólio de Ana Maria Nusdeo (2012, p. 23) existem três espécies de PSA: (i) conservação da biodiversidade; (ii) proteção das bacias hidrográficas; (iii) sequestro e estocagem de carbono e (iv) beleza cênica.

Especificamente em São Paulo apenas a segunda modalidade tem se desenvolvido, seja pela ausência de um mercado forte de ativos ambientais ou pela tradição do país em focar em políticas que envolvem o aspecto social. No atual modelo, conforme Marinho \& Castelo Branco (2014), o poder público assume o papel de comprador, intermediário e regulador, pois é ele quem edita normas, fiscaliza os projetos propostos e remunera o prestador de serviços ambientais.

Relativamente aos termos de outorga é imperioso que quem o recebeu aceitou de maneira expressa todos os seus termos e todas as condições a ele impostas, nas palavras de Milaré (2013, p. 927), estão estabelecidas em regulamento ou impostas segundo as circunstâncias de cada caso concreto, a juízo da autoridade competente do Poder Executivo Federal, dos Estados ou do Distrito Federal detentora de seu domínio.

Desta forma, cabe ao poder público a normatização e a concessão, bem como o acompanhamento permanente das atividades empresarias no ecossistema para que este possa se manter em bases sustentáveis e dentro de critérios considerados adequados para a equipe que se pronunciou quanto à oportunidade de concessão e garantia de conservação ecológica.

Para os autores é importante que as premissas do pagamento dos serviços ambientais são: “...que seja uma transação voluntária e, para tanto, os envolvidos devem estar motivados a participar; os serviços ambientais selecionados, ou uma modalidade de uso e ocupação dos solos, deve garantir a provisão desses serviços, necessariamente definido...”

Desta forma para que ocorra o PSA é fundamental que exista demanda de bens ambientais com um comprador específico, que deve garantir os recursos para essa compra. Os vendedores, por 
sua vez, ou quem encabeça a bacia ou comitê de bacias deve garantir a provisão e a qualidade dos serviços ofertados.

Não obstante essa possibilidade de oferta e demanda e viabilização de formulas para que um particular se aproprie de recursos ambientais Lage Novaes (2014) esclarece que:

\begin{abstract}
Pagamentos por serviços ambientais estão se tornando mais um mecanismo importante para promoção da sustentabilidade nas suas diversas dimensões... Diante de sua novidade e de abordagem relativamente nova, diferente e ainda renegada por muitos, o desenvolvimento do PSA e a própria execução de iniciativas e políticas de PSA estão em constante aperfeiçoamento, sendo, portanto, importante sua gestão de forma adaptativa, em função dos frequientes avanços teóricos e práticos.
\end{abstract}

O pagamento por serviços ambientais deve criar um ambiente de incentivos para que haja realmente a responsabilização daquele que usa os serviços e se apropria deles. Porém, importantíssimo que se estabeleça mecanismo permanente de monitoramento de seus impactos. O que pode ocorrer, como exemplo, é o fenômeno presentemente vivido na ocupação dos terrenos do bairro Água Limpa, próximo de Itabirito, na região metropolitana de Belo Horizonte (2018). Pela falta de monitoramento, segundo informou Francisco Mourão, biólogo da AMDA "Há uma redução significativa na vazão das nascentes em toda a região", Ainda afirma que desde que a fábrica iniciou suas atividades, várias comunidades, principalmente próximo a Brumadinho e Moeda, tiveram seus lençóis freáticos rebaixados. Segundo o biólogo há locais que inclusive são abastecidos por caminhões-pipa, e "alguns deles são enviados pela própria Coca-Cola".

Diante dessa ocorrência os comitês de bacias têm atuado dentro do que especificam as normas para monitorar a extração de água e verificar se as empresas estão efetivamente extraindo a água na proporção que se comprometeram. Em 2015, conforme o informe do sítio eletrônico "portal tratamento da água" em 2012, o Sistema Coca-Cola no Brasil, composto por um conjunto de nove empresas engarrafadoras, logrou alcançar a meta de devolver à natureza o dobro de água utilizada no processo produtivo, por meio de programas de reflorestamento e conservação de bacias hidrográficas, bem como de eficiência e reuso do recurso hídrico em suas respectivas fábricas.

Relativamente a essa ocorrência, uma das ONGs estabelecida no local afirmou que a fábrica da Coca-Cola do Município de Itabirito tem destruído a área verde. Segundo o sítio eletrônico “Ambiente Brasil" (2018), os ambientalistas ali presentes alegam que a unidade extrai 
mensalmente $173.253 \mathrm{~m} 3$ de água dos mananciais, sem apresentar estudos hidrogeológicos prévios, e denunciam que a fábrica foi instalada nos limites da Área de Proteção Ambiental Sul (APA SUL), o que contrariaria recomendações do Instituto Estadual de Florestas (IEF).

A empresa se defendeu alegando que "possui todas as licenças ambientais exigidas para seu regular funcionamento e, desde o início, seguiu todas as etapas necessárias para sua implantação, além de estar localizada no Distrito Industrial de Itabirito” (2018). Em suas informações afirmou que possui um estudo hidrogeológico indicando que sua atividade não interfere nos poços do SAAE Itabirito em relação à vazão das nascentes em Brumadinho.

Na composição dos Comitês PCJ grande parte de seus membros é constituída pelo poder público e os usuários conectados a este por interesse específico, a exemplo das companhias de água e esgoto. Diante desse quadro pode-se verificar que a composição favorece mais a articulação de diferentes instituições do próprio poder público e o debate de pautas interessantes aos setores econômicos. O que se pode afirmar, segundo Mario Masaru Sakaguti Júnior (2016, p.179) é que existe pouco envolvimento da sociedade civil organizada e o atendimento de suas respectivas demandas. Estas são as assimetrias encontradas nos comitês de bacias hidrográficas.

O autor segue em sua ilação no sentido de que a lógica dos comitês faz com que os atores envolvidos busquem mecanismos no sentido de diminuir práticas predatórias orientadas por interesses econômicos ou políticos. O próprio colegiado permite uma interação dinâmica em que os pleitos sejam colocados de forma transparente, de maneira a verificar a posição de todos os atores envolvidos: governos, empresas, usuários, sociedade civil. Essa composição permite que sejam evitadas práticas que possam gerar qualquer espécie de desvio.

É possível que efetivamente se esteja ingressando em um sistema em que a responsabilização e o monitoramento geram uma cultura saudável de negócios, focada na geração de valor econômico e ambiental ao mesmo tempo. As empresas agregadas ao consórcio devem buscar alternativas para aumentar a disponibilidade de água para a sociedade e evitar, a qualquer custo, que os sistemas hidrológicos gerenciados possam apresentar qualquer tipo de falha ou mesmo falta da quantidade necessária para o atendimento dos usuários da reigão.

\section{NECESSIDADE DE MONITORAMENTO}

A Conferência de Estocolmo (1972) já alertava que para se chegar à meta da sustentabilidade é fundamental que se orientem os atos em todo o mundo com relação às consequências que

Rev. de Direito Agrário e Agroambiental | e-ISSN: 2526-0081 | Porto Alegre | v. 4 | n. 2 | p. 55 - 70 | Jul/Dez. 2018 
podem gerar em termos ambientais. Nesse sentido instituições, comunidades, empresas e instituições devem aceitar as responsabilidades impostas. As administrações locais de nacionais e as respectivas jurisdições são as responsáveis pela maior parte do estabelecimento de normas e aplicações de medidas em prol do ambiente.

Nesse sentido, novos ramos jurídicos, tal como o Direito Ambiental surgem em prol de estabelecer medidas a serem observadas. Como é um ramo jurídico interdisciplinar é fundamental que outras ciências possam auxiliar os diversos profissionais envolvidos na liberação de recursos naturais para consumo individual, tal como ocorre comumente com o pagamento dos serviços ambientais.

O monitoramento da qualidade das águas naturais consiste na verificação de possíveis alterações nas características químicas, físicas e biológicas da água, que possam ser objeto de alguma modificação diante da atividade humana conectada a água e também coligadas a fenômenos naturais.

Esse monitoramento corresponde basicamente à coleta de dados e de amostras de água em locais específicos. Esta amostragem é efetivada em intervalos regulares de tempo, de maneira a produzir informações capazes de a gerar informações viáveis de ser empregadas para a definição real da qualidade da água. Além disso, juntamente com esse monitoramento é feita a determinação de vazão, de maneira a detectar a carga de poluentes.

Nos termos do Portal "Qualidade das Águas" (2018) essa forma procedimento objetiva viabilizar uma avaliação própria da qualidade da água. Nesse processo é possível se estabelecer: pontos de monitoramento previamente delimitados, periodicidade da captação de amostras e o tipo de parâmetros monitorados. Segundo informação da ANA existem algumas espécies de monitoramento: o monitoramento básico com o objetivo de se verificar a evolução da qualidade das águas, identificação de tendências e apoio a elaboração de diagnósticos. Outro tipo possível de levantamento é o efetivado por inventários em que a análise é extraída de determinados trechos de água para avaliar se determinados parâmetros previamente definidos estão sendo atendidos, sobretudo relacionados à qualidade da água. Ainda se pode mencionar a vigilância, em que as observações são efetuadas em locais cuja extração é fundamental para consumo humano ou ainda em locais em que a poluição seja considerável crítica. A terceira modalidade de monitoramento é o "de conformidade" cujo resultado final contará com a opinião dos usuários dos recursos hídricos por meio de um auto-monitoramento, em atendimento a 
requisitos legais presentes em marcos regulatórios (Portaria no 518 do Ministério da Saúde, Resolução no 357 do CONAMA).

O monitoramento das águas não depende unicamente de fatores previamente definidos que devam servir de parâmetro. Sob o escólio de Gelting e Baloch (2013) além da análise realizada com base nas diversas variáveis escolhidas para a análise esta deve permitir uma visão holística e multidisciplinar; é fundamental que se aplique uma avaliação ambiental em um conjunto de atividades. Isto viabilizará a verificação real da qualidade da água, a saúde ambiental, a irrigação, o manejo e a gestão das bacias hidrográficas.

Na hipótese de ser detectada a exploração dos recursos hídricos em bases não sustentáveis é essencial que setores da sociedade tomem a dianteira para sua respectiva proteção, sobretudo o setor público e outros setores. A realidade comprova que a água frequentemente é empregada de forma indiscriminada, sem os devidos cuidados. Se medidas corretivas não forem rapidamente tomadas, a qualidade das águas decairá bruscamente impedindo manter o recurso para as futuras gerações. A necessidade de se monitorar os ambientes aquáticos existe para que se possa fazer o acompanhamento de uma bacia hidrográfica. A qualidade da água deve ser monitorada de maneira a permitir uma ampla correção pontual de poluentes e verificação do entorno em termos de impacto ao ambiente existente.

A gestão adequada do monitoramento dos recursos hídricos deve contar com políticas públicas criteriosas que levem em consideração fatores diversos. A manutenção e preservação de todos os serviços ambientais e socioeconômicos, dos quais os reservatórios são responsáveis, depende de uma gestão com uma abordagem ecossistêmica.

Na obra de Enrique Leff (2015, p. 24-27) fica claro que o discurso do desenvolvimento sustentável e da legislação ambiental gera uma nova forma de solidariedade ecológica e social. Os conflitos ambientais emergem do conflito de interesse e estratégias diferenciadas de apropriação e aproveitamento da natureza. Um dos grandes impactos, segundo o autor, é a exploração de hidrocarbonetos e usufruto das riquezas do solo e do subsolo, além de toda flora e fauna. O problema não se limitaria a compensações sobre o dano nos sistemas explorados ou aos benefícios derivados da exploração de recursos.

O autor segue afirmando que as lutas ecológicas e os direitos ambientais não são apenas reivindicações econômicas. São também lutas pelo direito e pela segurança humana para reduzir 
e evitar o risco ecológico que se incrementa com o interesse econômico, pela introdução de práticas novas que podem esgotar a biodiversidade.

Ainda que haja equipe responsável pela verificação do volume de água, in casu, ou ainda outras formas de manejo profissionais em que se assumem riscos programados e possíveis, há ainda uma importante variável que deve ser efetivamente considerada nos processos de concessão de serviços ambientais relacionados à água: o clima.

Nesse aspecto recorremos à opinião de Motta (2011), que fez estudos em âmbito estadual e municipal, que destaca a Política Nacional sobre Mudança do Clima (PNMC), que deve contar com uma estrutura de governança autônoma e transparente para evitar desvios resultantes tanto da influência e dos interesses regulados como de mudanças de governo e oportunismo político.

Aspecto fundamental é que os elementos climáticos variam de acordo com a localidade. São eles: pressão atmosférica, precipitação de chuva, umidade e temperatura atmosférica. É notório que a morfologia geográfica e a configuração antrópica do espaço interfere diretamente nos estados do tempo e, consequentemente, no clima atmosférico sobre o local. Não somente a altitude, a densidade vegetal, a hidrografia e o adensamento populacional urbano são fatores influenciadores do clima em locais determinados. Isso pode ser constatado pelas ilhas de calor em centros urbanos e a diferença com o meio rural, cuja temperatura entre ambas pode chegar a $10^{\circ}$ (MARENGO, 2013).

\section{CONSIDERAÇÕES FINAIS}

A Constituição Federal vigente assegurou um meio ambiente adequado para as presentes e futuras gerações no art. 225. A água também está incluída nesta proteção. É um bem ambiental precioso. Dela depende toda a vida na terra.

O Comitê de Bacia Hidrográfica é um órgão colegiado que possui atribuições normativas, deliberativas e consultivas. Por este motivo funciona como um verdadeiro "parlamento das águas". Atua como instancia direta dos grupos decisórios organizados em cada bacia e sua força decisória pode identificar a junção de entes federativos em forma de consórcio e a bacia nem sempre respeita limites geográficos, já que a extensão do rio delimita a competência do órgão de decisão. Aqui se deu como um exemplo a ser seguido o modelo empregado na Bacia PCJ Piracicaba, Capivari e Jundiaí, como tendo uma maturação adequada em termos de comitê. 
A gestão das águas deve envolver processos deliberativos em que haja a fundamental participação de todos os interessados, sobretudo daqueles que tenham a condição de participar negociar como integrantes próprios do comitê. Essa circunstância é fundamental na gestão dos comitês, pois garante legitimidade e participação tal como determina a Constituição Federal e normas relacionadas aos entes federativos.

O pagamento pelos serviços ambientais está em relevo nos dias atuais, seja pelo desenvolvimento doutrinário do tema, seja por seu estabelecimento na legislação de determinados estados brasileiros. É fundamental que se precifique e estabeleçam condições para a concessão de recursos naturais e trata-se de modalidade de incentivo a condutas favoráveis ao tratamento do ambiente no Brasil. Entretanto, seu monitoramento é ainda mais importante para que os recursos não se esgotem, tal como ocorrido em Minas Gerais onde se constatou destruição da vegetação local e significativa diminuição de água dos mananciais. Nessa situação apontou-se que estudos hidrogeológicos prévios poderiam antever problemas que ocorreram na região.

Outro elemento verificado neste trabalho enfoca a questão climática. Esta deve ser objeto de estudo na outorga de serviços ambientais, pois é uma constante a existência de mudanças bruscas por excesso de desmatamento ou ainda outras intervenções antrópicas.

Como observado ainda a legislação está em vias de aprimoramento. Fundamental, portanto, que haja a previsão de um comitê que possa prever problemas relacionados ao clima, bem como seja ainda responsável por condutas transparentes que possam garantir concessões com racionalidade e equilíbrio e que as regras de prevenção e precaução sejam efetivamente consideradas para que mais uma vez o ambiente não pague pelos danos gerados pelos infratores.

\section{REFERÊNCIAS}

AMBIENTE BRASIL. ONG afirma que fábrica da Coca-Cola está destruindo meio ambiente. Disponível em < http://noticias.ambientebrasil.com.br/clipping/2018/04/23/143238ongafirma-que-fabrica-da-coca-cola-esta-destruindo-meio-ambiente.html >. Acesso em 29.08.2018.

BRASIL, Lei Federal n .9433, de 8 de janeiro de 1997. Dispõe sobre a Política Nacional de Recursos Hídricos. Disponível em < http://www.planalto.gov.br/ccivil_03/Leis/19433.htm>, acesso em Acesso em 20.05.2018 .

BRASIL. Agência Nacional de Águas - ANA. Disponível em < http://www3.ana.gov.br/>, acesso em 21.06.2018. 
COIMBRA R.; ROCHA C.L.; BEKMAN, G.B. Recursos hídricos: conceitos, desafios e capacitação. Brasilia: ANEEL, 1999.

CUNHA, Belinda Pereira da; AUGUSTIN, Sérgio; LIMA, Leticia Gonçalves Dias; COSTA, Nálbia Roberta Araújo da (orgs). Os saberes ambientais, sustentabilidade e olhar jurídico: visitando a obra de Enrique Leff. Caxias do Sul: Educs, 2015.

GELTING, R. J.; BALOCH, M. Systems analysis of irrigation water quality in environmental assessments related to foodborne outbreaks. Aquatic Procedia, New York, v. 1, p. 130-137, 2013.

GRANZIERA, Maria Luiza Machado. Direito ambiental. São Paulo: Atlas, 2014.

HADDAD, Paulo R. Pagamento por serviços ambientais. Disponível em <HTTPS://www,ecodebate.com.br/2013/01/01/pagamento-por-serviços-ambientais-artigo-depaulo-r-haddad>. Acesso em 20.05.2018.

MARENGO, J.A.; VALVERDE, M.C.; OBREGON G.O. Observed and projected changes in rainfall extremes in the metropolitan area of São Paulo. In Climate REsearch, v. 57, pp. 61-72, jul 2013.

MASCARENHAS, A.C. Comitê de bacia hidrográfica: o que é, como funciona e que papel desempenha na gestão dos recursos hídricos. In Plenarium, ano III, n. 3. Brasilia: Câmara dos Deputados, Coordenacao de Publicações, 2006.

MACHADO, Paulo Affonso Leme. Direito ambiental brasileiro. São Paulo: Malheiros, 2011.

MARINHO, Yuri Rugai e CASTELO BRANCO, Carolina. Relatório de São Paulo. In Sistemas estaduais de pagamento por serviços ambientais: relatórios estaduais: diagnóstico, lições aprendidas e desafios para a futura legislação. LAVRATTI, Paula et al. (orgs). São Paulo: Instituto o direito por um planeta verde, 2014.

MILARÉ, Edis. Direito do ambiente. São Paulo: Ed. Revista dos Tribunais, 2013.

MOTTA, Ronaldo Seroa. A política Nacional sobre Mudanças do Clima: aspectos regulatórios e de governança. Cap 1. In: MOTTA et al. (Ed). Mudança do Clima no Brasil, aspectos econômicos, sociais e regulatórios. Brasília, IPEA, 2011.

NUSDEO, Ana Maria. Pagamento por Serviços Ambientais; sustentabilidade e disciplina jurídica. São Paulo: Atlas, 2012.

NUSDEO, Ana Maria. Direito ambiental e economia. Curitiba: Juruá Ed, 2018. ONU Organização das Nações Unidas - Conferência de Estocolmo de 1972. Disponível em. Acesso em 08.05.2018.

RIBEIRO, Cristina Bernardes. A importância dos Comitês de Bacia na Gestão dos Recursos Hídricos. Tese de Mestrado da UNB, Orientadora Profa. Dra Marilia Steinberger. Brasília-DF, agosto de 2006. PORTAL G1 NATUREZA. Biólogos acusam Coca-Cola de secar nascentes em Minas Gerais. Disponível em < https://g1.globo.com/natureza/noticia/biologos-acusamcoca-cola-de-secar-nascentesem-minas-gerais.ghtml>. Acesso em 4/06/2018.

SAKAGUTI JUNIOR, Mario Masaru. Gestão, governança e uso das águas no Brasil e em Singapura: um estudo dos casos da ilha principal de Singapura e das bacias hidrográficas dos

Rev. de Direito Agrário e Agroambiental | e-ISSN: 2526-0081 | Porto Alegre | v. 4 | n. 2 | p. 55 - 70 | Jul/Dez. 2018 
rios Piraciicaba, Capivari e Jundiaí, SP/MG. Tese de doutorado apresentado em ecologia aplicada na Escola Superior de Agricultura Luiz de Queiroz. Orientador ALMEIDA JR., Antonio Ribeiro de. Centro de Energia Nucleas na Agricultura. Piracicaba, 2016.

SÃO PAULO. Disponível em

<www.comitespcj.org.br/index.php?option=com_content\&view=article\&id=28\&itemid +108 $>$.Acesso em 6.6.2018. 